\title{
EFEITO DA PODA ANTECIPADA E REGIME DE IRRIGAÇÃO NOS TEORES DE AÇÚCARES EM UVAS 'NIÁGARA ROSẢDA'
}

\author{
Effect of antecipated pruning and irrigation regime on the sugar \\ contents in 'Niágara Rosada' grapes
}

\author{
Richardson Júnior Lacerda Silva ${ }^{1}$, Luiz Carlos de Oliveira Lima², Nilton Nagib Jorge Chalfun ${ }^{3}$
}

\begin{abstract}
RESUMO
O experimento foi conduzido em um pomar comercial, localizado no município de Lavras - MG, objetivando-se com este trabalho avaliar o efeito da poda antecipada no teor de açúcares da uva 'Niagara Rosada' (Vitis labrusca L.). Os tratamentos empregados corresponderam à diferentes épocas de poda de frutificação, sendo realizada, respectivamente, em 03/05/2004, 17/05/2004, 31/05/2004, 15/06/2004, 29/06/2004, 13/07/2004 (podas antecipadas), 20/07/2004 e 03/08/2004 (podas tradicionais, com e sem regime de irrigação). Para avaliar a qualidade das uvas 'Niágara Rosada' quanto ao teor de açúcares realizaram-se, as seguintes análises: açúcares totais, açúcares redutores (glicose e frutose) e relação frutose/glicose. Para execução das análises foram retiradas as sementes e trituradas as bagas com casca e polpa. Verificou-se que a qualidade dos frutos colhidos fora do pico de produção, ou seja, poda antecipada, atendem aos padrões de qualidade exigidos pela legislação e que a irrigação compromete o teor de açúcares na uva, reduzindo os mesmos.
\end{abstract}

Termos para indexação: Colheita, antecipação da safra e padrões de qualidade.

\begin{abstract}
The experiment was conducted at a commercial orchard situated in the municipality of Lavras - MG, with the objective of evaluating the effect of anticipated pruning on the sugar content of 'Niagara Rosada' grape (Vitis labrusca L.). The treatments employed corresponded to different times of pruning for fructification, being performed on May $5^{\text {th }} 2004$, , May $17^{\text {th }} 2004$, May $3^{\text {rd }}$ 2004, June $15^{\text {th }} 2004$, June $29^{\text {th }} 2004$, July $13^{\text {th }} 2004$ (for anticipated prunings), July $20^{\text {th }} 2004$ and August $3^{\text {rd }} 2004$ respectively, for traditional prunings, with and without irrigation regime. To evaluate the quality of 'Niágara Rosada' grapes regarding the sugar content, the following analyses were accomplished: total sugars, reducing sugars (glucose and fructose), and fructose/glucose ratio. To accomplish the analyses, the seeds were taken out and the berries were ground, with their skin and pulp. The quality of the fruits harvested during periods that do not include the peak production, that is, fruits originated from anticipated pruning, was in accordance with the quality standards demanded by the legislation. It was also observed that irrigation hinders the sugar production in the grape, reducing its content.
\end{abstract}

Index terms: Harvest, early fruit yield and quality.

(Recebido em 18 de maio de 2006 e aprovado em 2 de abril de 2007)

\section{INTRODUÇÃO}

Devido à sazonalidade climática, a produção de uvas na região sul e sudeste do Brasil é restrita a alguns períodos do ano. Na região sul de Minas, sua colheita concentra-se nos meses de dezembro a fevereiro, coincidindo com a produção de Jundiaí - SP, tendo este panorama levado a uma oferta de grande quantidade de uva 'Niágara Rosada' nos meses de dezembro, janeiro e fevereiro, quando os preços caem vertiginosamente. Nesse contexto, o produtor que conseguir antecipar sua safra obterá maiores lucros. Para isso, o uso de práticas que visem a alterar o ciclo produtivo da videira, buscando uma antecipação do período de colheita seria uma opção para aumentar o período de oferta. Além da necessidade de se estudar formas de antecipação da safra, como meio de se alcançar melhores preços de mercado, torna-se necessário também a obtenção de produtos que atendam às características mínimas de qualidade exigidas pelo consumidor brasileiro, tais como: equilíbrio entre ácidos e açúcares, coloração atrativa, aroma característico (GONÇALVES, 2005).

De acordo com Pereira (2001), o município de Lavras tem sua economia agrícola assentada no binômio café/ leite, necessitando-se, dessa forma, de uma outra opção rentável que venha maximizar a utilização da pequena

\footnotetext{
'Biólogo, Mestre em Ciências dos Alimentos - Departamento de Ciência dos Alimentos/DCA- Universidade Federal de Lavras/UFLA - Campus Universitário - Cx. P. 3037 - 37200-000 - Lavras, MG - lacerda28@ufla.br

${ }^{2}$ Farmacêutico Bioquímico, Doutor em Fisiologia Pós-Colheita de Frutos e Hortaliças - Departamento de Ciência dos Alimentos/DCA- Universidade Federal de Lavras/UFLA - Campus Universitário - Cx. P. 3037 - 37200-000 - Lavras, MG - Icolima@ufla.br

${ }^{3}$ Engenheiro Agrônomo, Doutor, Professor Titular - Departamento de Agricultura/UFLA - Universidade Federal de Lavras/UFLA - Campus Universitário Cx. P. 3037 - 37200-000 - Lavras, MG - nchalfun@ufla.br
} 
propriedade rural, na busca da geração de empregos e aumento da renda familiar. A cultivar 'Niágara Rosada' completa seu ciclo mediante temperaturas superiores a $10^{\circ} \mathrm{C}$, e, baseado no conceito graus-dia (GD), a necessidade térmica dessa cultivar para se desenvolver da poda à colheita é de 1549 graus-dia, independente da época da poda. Ao comparar as normais climáticas de Caldas, principal produtor de uvas na região sul de Minas e Lavras - MG, Abrahão et al. (2002), verificou-se, que a soma das temperaturas ativas (acima de $10^{\circ} \mathrm{C}$ ), durante o período de vegetação da videira (agosto a fevereiro) atinge 2361,23 graus-dia em Lavras, contra apenas 1954,87 graus-dia em Caldas, alcançando uma diferença de 406,36 graus-dia na totalidade do ciclo. Portanto, verificou-se diante do exposto que o município de Lavras apresenta condições climáticas favoráveis à pratica da poda antecipada. Neste trabalho, objetivou-se avaliar as características química de uvas 'Niagara Rosada' (Vitis labrusca L.) submetidas a poda antecipada, visando a obtenção de uvas de qualidade fora do pico de produção.

\section{MATERIAL E MÉTODOS}

O experimento foi conduzido em um pomar comercial, localizado no município de Lavras - MG, na região Sudeste do Brasil, a $21^{\circ} 14^{\prime} 06^{\prime \prime}$ de latitude sul, $45^{\circ} 00^{\prime} 00^{\prime \prime}$ de longitude Oeste e altitude de 918,841 metros. O clima da região é Cwa de acordo com a classificação de Kopper. O vinhedo no qual realizou-se o experimento foi implantado em junho de 1998, utilizando como copa a 'Niágara Rosada' e como porta enxerto a cultivar Vitis riparia [V. rupestris $x \mathrm{~V}$. cordifolia (106-8 Mgt)], conhecida como Traviú. O sistema de condução empregado foi o suporte espaldeira, com as plantas conduzidas em cordão esporonado bilateral, com espaçamento de 3,00 x 2,00 metros (1667 plantas/ ha) e sistema de irrigação localizada do tipo gotejo e o solo classificado como Latossolo Vermelho Eutrófico. Os tratamentos empregados corresponderam a diferentes épocas de poda de frutificação, sendo realizada, respectivamente, em 03/05/2004, 17/05/2004, 31/05/2004, 15/ 06/2004, 29/06/2004, 13/07/2004 (podas antecipadas), 20/ 07/2004 e 03/08/2004 (podas tradicionais, com e sem regime de irrigação). A poda foi do tipo curta, com os esporões mantidos com duas gemas. Foram utilizadas quatro plantas para cada tratamento distribuídas em três repetições. Utilizou-se Dormex® (6\%) após a poda para auxiliar na quebra de dormência. Para avaliar a qualidade das uvas 'Niágara Rosada' quanto ao teor de açúcares executou-se as seguintes análises: açúcares totais, açúcares redutores (glicose e frutose); para determinação dos açúcares totais e redutores foi extraído o suco da uva através da trituração em politron e determinado através do método de Somogyi, adaptado por Nelson (1944). A leitura foi realizada em espectrofotômetro Beckman 640B, à $510 \mathrm{~nm}$ com sistema computadorizado e os resultados expressos em porcentagem $(\%)$. A porcentagem de sacarose (açúcares não redutores) foi obtida pela diferença entre os teores de açúcares totais e redutores, antes e depois da hidrólise ácida. A diferença entre os dois valores, multiplicada pelo fator 0,95 (fator de conversão do açúcar invertido em sacarose), dará a quantidade de sacarose existente na solução. Relação frutose/glicose, A determinação da frutose foi feita segundo método de Ribéreau-Gayon \& Peynaud. O método é baseado na coloração azul que a frutose forma em meio ácido, quando reage com a difenilamina. A coloração foi extraída com álcool amílico e lida no espectrofotômetro a $640 \mathrm{~nm}$; a glicose foi determinada pela diferença entre teores de açúcares redutores totais obtidos por Somogy (NELSON, 1994) e frutose $(\mathrm{G}=$ açúcares redutores - frutose). A relação Fru/ Glu foi determinada pelo resultado da divisão entre os teores de frutose pelos teores de glicose.

Para execução das análises foram retiradas as sementes e trituradas as bagas com casca e polpa. Todas as análises foram executadas em triplicata para maior confiabilidade nos resultados. O experimento foi realizado coletando-se amostras compostas em blocos casualisados, com três repetições da cultivar Niágara Rosada submetidas a oito épocas de poda, sendo os mesmos divididos nos seguintes regimes hídricos: 1- Plantas irrigadas e 2 não irrigadas (fatorial 8 x 2). Utilizou-se como amostra o suco extraído de 30 bagas tomadas ao acaso em cada repetição.

\section{RESULTADOS E DISCUSSÃO}

Os resultados para os teores de açúcares totais de frutos da videira 'Niágara Rosada' em função da irrigação e diferentes épocas de poda são apresentadas, na Figura 1, onde se observa que houve diferença significativa, $(\mathrm{p}<0,05)$, para a característica avaliada em função da interação época de poda e regime hídrico.

Na Figura 1 estão apresentados os resultados do efeito da época de poda no teor açúcares totais, permitindo observar que as plantas sem regime de irrigação obtiveram valores mais elevados em relação às irrigadas. $\mathrm{O}$ fato pode ser explicado segundo Gonçalves (2005) pela influência da irrigação, reduzindo os teores de açúcares pela diluição dos mesmos. Os teores de açúcares totais analisados encontram-se de acordo com o requerido pela legislação brasileira (BRASIL, 1974), que determina valores entre $12 \mathrm{e}$ $25 \%$ para elaboração de suco integral. 
SILVA, R. J. L. et al.

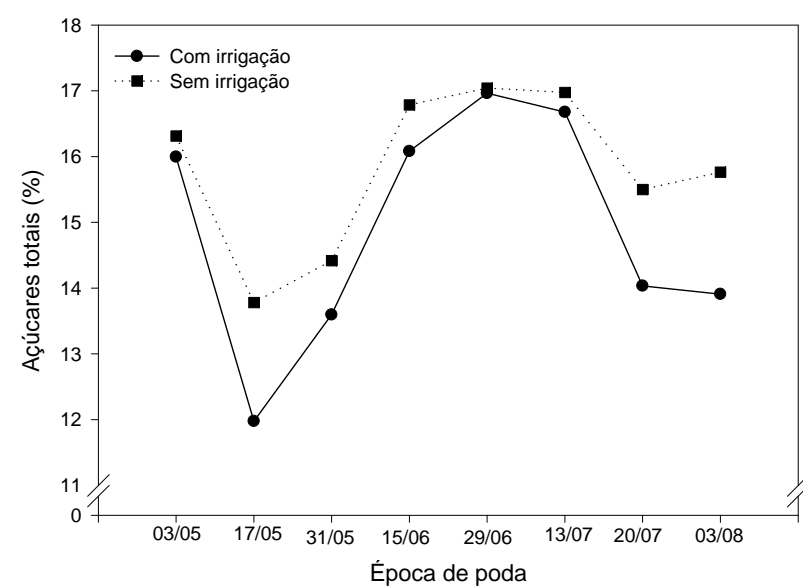

Figura 1 - Valores médios observados de açúcares totais em uvas "Niagara Rosada" submetidas a diferentes épocas de poda e diferentes regimes hídricos, UFLA, 2006.

Pelos dados apresentados na Figura 1, observa-se ainda que em relação às épocas de poda, as que apresentaram maiores valores de açúcares foram os frutos das plantas podadas em 15/06 (4), 29/06 (5) e 13/07 (6). Esse aumento no valor de açúcares totais para essas datas pode estar relacionado com o menor índice pluviométrico e maiores temperaturas registradas na fase de desenvolvimento dos frutos. Nota-se também que nas três primeiras datas de poda, a data $1(03 / 05)$, data $2(17 / 05)$ e data $3(31 / 05)$, mesmo apresentando valores de açúcares aceitáveis pela legislação, os cachos e bagas apresentaram tamanhos reduzidos (volume e número) e, por esta razão, não se enquadraram aos padrões de qualidade e por isso não apresentaram valor comercial (GONÇALVES, 2005; SANTANA, et al., 2008).

Na Figura 2, são apresentados os resultados do efeito da época de poda e regime hídrico no teor de açúcares redutores (glicose e frutose), onde houve diferença significativa, $(\mathrm{p}<0,05)$, para a interação época de poda e regime hídrico. Os maiores valores conseguidos em todas as épocas são observados para plantas sem regime de irrigação e os mesmos são satisfatórias para os padrões de qualidade da cultivar. Os teores de açúcares redutores encontrados no presente estudo, apresentaram valores semelhantes aos citados na literatura. No presente trabalho houve predominância dos açúcares redutores em relação aos não redutores.

Em relação à concentração dos açúcares presentes na uva, Rizzon \& Miele (1995) citam valores médios de 18\% para os açúcares totais. Pezzi \& Fenocchio (1976) encontraram valores de açúcares totais que variam entre $13 \%$ a $18 \%$, e para sacarose, variou de 1,5\% até inexistente.

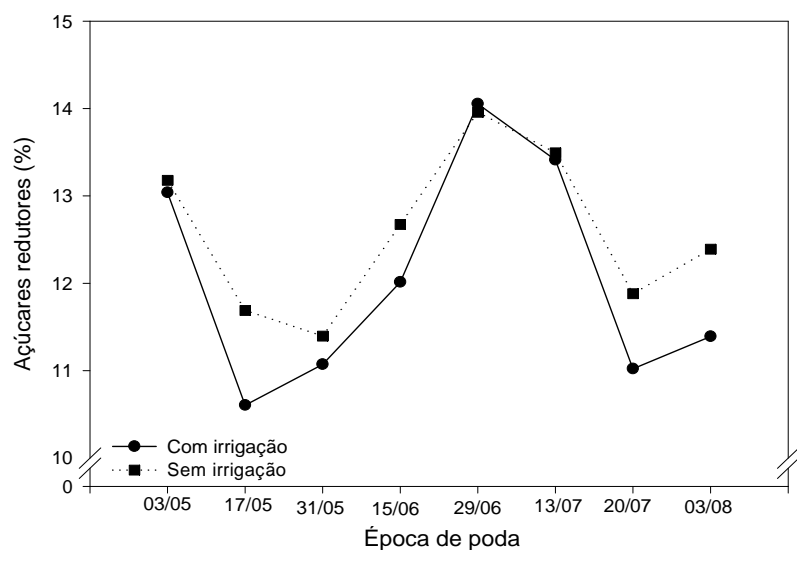

Figura 2 - Valores médios observados de açúcares redutores em uvas "Niagara Rosada" submetidas a diferentes épocas de poda e diferentes regimes hídricos, UFLA, 2006.

Pezzi \& Fenocchio (1976) e Pereira (2001), citam valores de açúcares totais para o suco de uva elaborado na Itália variando de 12 a 17\%. De acordo com Rizzon \& Mielle (1995), a concentração total de açúcares para o suco de uva varia de 14 a $18 \%$. Blouin \& Guimberteau (2000) encontraram valores de açúcares redutores entre $16 \%$ e $25 \%$ para cultivares européias. Pereira (2001) cita valores de glucose e frutose (açúcares totais), encontrados para as cultivares Isabel, Concord e Folha de figo ( $16 \%, 18 \%$ e $15 \%$ ) respectivamente (SANTANA, et al., 2008).

Os resultados para a relação frutose/glicose em frutos da videira 'Niágara Rosada' em função da irrigação e diferentes épocas de poda encontram-se na Figura 3.

Observou-se que houve diferença significativa, $(\mathrm{p}<0,05)$, para a característica avaliada, em função da interação época de poda e regime hídrico.

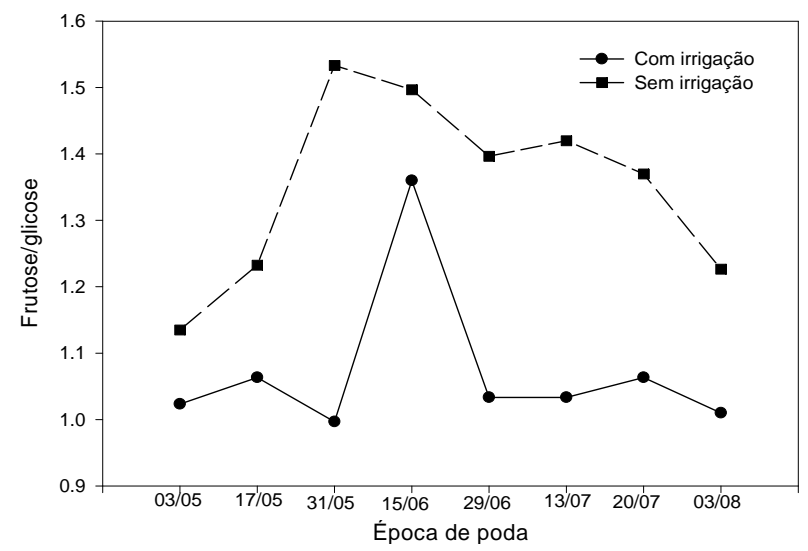

Figura 3 - Valores médios observados relação frutose/ glicose em uvas "Niagara Rosada" submetidas a diferentes épocas de poda e diferentes regimes hídricos, UFLA, 2006. 
As plantas podadas no mês de junho, apresentaram maiores valores para a relação frutose/glicose. Segundo (CARVALHO, 1972; CARVALHO et al., 2008), o aumento nos açúcares é devido principalmente a um acréscimo nos teores de glicose e frutos, e sendo que no início da maturação, o primeiro apresenta-se superior ao segundo e no final tendem a ter níveis relativamente iguais, sendo que quanto maior este índice, maior o teor de frutose e mais doces podem ser considerados os frutose. Observou-se, portanto, que os valores desta relação, tanto para as plantas irrigadas quanto para as não irrigadas, tiveram valores superiores a 1, mostrando que a frutose apresentou aumentos contínuos até ao final da maturação. A Figura 3 mostra ainda que as plantas irrigadas obtiveram uma pequena variação nos níveis desta relação, ou seja, bem próximos a 1 exceto, para os frutos das plantas podadas em 15/06. As uvas das plantas sem regime de irrigação atingiram valores mais elevados, permitindo assegurar que as podas do mês de junho proporcionaram condições climáticas mais favoráveis ao acúmulo de açúcares em relação às demais datas.

\section{CONCLUSÕES}

Os frutos colhidos fora do pico de produção (safra antecipada) atendem aos padrões de qualidade quanto aos teores de açúcares, exigidos pela legislação brasileira.

A irrigação provoca alterações nas características químicas da uva, reduzindo seus valores não sendo recomendado seu uso no período de maturação dos frutos, ou seja meses próximos à colheita.

A época de poda pode exercer grande influência na composição química (açúcares, acidez, pH etc) dos frutos devido à influencia das condições climáticas ao longo do ciclo das plantas.

\section{REFERÊNCIAS BIBLIOGRÁFICAS}

ABRAHÃO, E.; ALVARENGA, A. A.; FRÁGUAS, J. C.; REGINA, M. A.; SILVA, V. J. Potencialidade do município de Lavras-MG para produção extemporânea de uvas

'Niágara Rosada'. Ciência e Agrotecnologia, Lavras, v. 26, n. 4, p. 865-868, jul./ago. 2002.

BLOUIN, J.; GUIMBERTEAU, G. Maturation et Maturité des raisins. Paris: Férret-Fr, 2000. 151 p.

BRASIL. Ministério da Agricultura. Secretaria nacional de defesa Agropecuária. Secretaria de Inspeção de Produtos Vegetais. Complementação de padrões de qualidade para suco de uva. Brasília, DF, 1974. 29 p.
CARVALHO, V. de. Algumas características de uvas cultivadas no município de Caldas (MG), com vistas do aproveitamento industrial do produto. 1972. $65 \mathrm{f}$. Tese (Doutorado em Ciências dos Alimentos) - Universidade de São Paulo, São Paulo, 1972.

CARVALHO, G. L. DE.; LIMA, L. C. DE. O.; SILVA, J. D.; SIQUEIRA, H. H.; MORAIS, E. C. Concentrações de cloreto de cálcio e tempos de armazenamento nos teores de açúcares redutores de uvas cv red globe (Vitis vinifera L). Ciência e Agrotecnologia, Lavras, v. 32, n. 3, p. 894-899, maio./jun. 2008.

GONÇALVES, F. C. Antecipação na produção da videira 'Niagara Rosada' na região de Lavras, MG. 2005. 71 p. Tese (Doutorado em Fitotecnia) - Universidade Federal de Lavras, Lavras, 2005.

NELSON, N. A. A photometric adaptation of Somogy method for the determination of glucose. Journal of Biological Chemistry, Baltimore, v. 135, p. 136-175, 1944.

PEREIRA, G. E. Caracterização agronômica de cultivares de videira para suco em Minas Gerais: avaliação analítica e sensorial dos sucos. 2001. 126 p. Dissertação (Mestrado em Fisiologia Pós-Colheita) Universidade Federal de Lavras, Lavras, 2001.

PEZZI, G. M.; FENOCCHIO, P. Estudo analítico dos sucos de uvas comerciais. Pesquisa Agropecuária Brasileira, Brasília, v. 11, p. 11-13, 1976.

RIZZON, L. A.; MIELE, A. Características analíticas de suco de uvas elaborados no Rio Grande do Sul. Boletim da Sociedade Brasileira de Ciência e Tecnologia de alimentos, Campinas, v. 29, p. 129-133, 1995.

SANTANA, M. T. A.; SIQUEIRA, H. H. DE.; REIS, K. C. DOS; LIMA, L. C. DE. O.; SILVA, R. J. L. Caracterização de diferentes marcas de sucos de uva comercializados em duas regiões do Brasil. Ciência e Agrotecnologia, Lavras, v. 32, n. 3, p. 882-886, maio./jun. 2008.

SANTANA, M. T. A.; SIQUEIRA, H. H. DE.; LACERDA, R. J.; LIMA, L. C. DE. O. Caracterização físico-química e enzimática de uva "Patrícia" cultivada na região de Primavera do Leste - MT. Ciência e Agrotecnologia, Lavras, v. 32, n. 1, p. 186-190, jan./fev. 2008. 